\title{
Performance Investigation of Building Ventilation System by Calculating Comfort Criteria through HVAC Simulation
}

\author{
Tousif Ahmed ${ }^{1}$, MD.Ziaur Rahman ${ }^{2}$ \\ ${ }^{1,2}$ (Department of Mechanical Engineering, Bangladesh University of Engineering and Technology, \\ Bangladesh)
}

\begin{abstract}
This paper describes a study of the performance of a ventilation system in a typical patient room using CFD modeling and calculations of various ventilation indices. The principal purpose of heating, ventilating and air conditioning systems (HVAC) is to provide conditions for human thermal comfort. Flow simulations with the advent of computer architectures with superfast processing capabilities are rapidly emerging as an attractive alternative to conventional HVAC analysis which is either too restrictive or expensive. Design and operation of a typical ventilation system is fully investigated in this study through HVAC flow simulation. A tool of computational fluid dynamics (CFD) is employed to assist the process. The objective is to investigate ventilation system while maintain good indoor thermal and air quality. The Model was designed into Solidworks and a computational domain was created. Solidworks Flow Simulation was used to iterate toward a converged solution with the goal of obtaining comfort criteria of the ventilation system. The results were analyzed and compared with standard values of thermal comfort criteria to validate those results.
\end{abstract}

Keywords -HVAC, SolidWorks, simulation, comfort criteria, ventilation, AQI, PPD, PMV

\section{Introduction}

The indoor environmental quality (IEQ) and occupant comfort are closely related. The current indoor environmental assessment includes four aspects, namely thermal comfort (TC), indoor air quality (IAQ), visual comfort (VC) and aural comfort (AC). IAQ, as the nature of air in an indoor environment with relation to the occupant health and comfort is not an easily defined concept. In a broad context, it is the result of complex interactions between building, building systems and people. It is a common practice to assess the performance of a ventilation system by some standard criteria, named comfort parameters. With "Flow Simulation" one can simulate various environments and get the values of comfort parameters, determining whether the air quality and temperature are safe and comfortable for people working or living in those environments. Here, a hospital isolation room was considered and the ventilation system effectiveness with respect to the contaminant removal and thermal satisfaction of people in the room was estimated. A typical patient room includes standard features such as a patient bed, exhausts, lightening, and equipment. The overhead ventilation system contains an overhead ceiling supply diffuser, the ceiling and the washroom exhausts. The contaminant source is assumed to be the patient breathing. The heat sources are lights, medical equipment, a TV, a patient and a caregiver.

The following parameters are used to estimate the ventilation system effectiveness with respect to contaminant removal: Contaminant Removal Effectiveness (CRE) and Local Air Quality Index (LAQI).

The following parameters are used to estimate the ventilation system effectiveness with respect to thermal satisfaction of people: Air Diffusion Performance Index (ADPI), Predicted Mean Vote (PMV) and Predicted Percent Dissatisfied (PPD).

\section{Comfort Criteria}

The A widely accepted definition of thermal comfort is, "Thermal Comfort is that condition of mind that expresses satisfaction with the thermal environment" (ASHRAE 1992).

One method of assessing the thermal comfort is to use the equations for predicted mean vote (PMV) and predicted percentage dissatisfied (PPD) produced by Fanger and given in the ASHRAE Handbook (ASHRAE 1997). These equations are based on an empirical investigation of how people react to differing environments. It is well known that different people will have a different perception of the climate produced in a building, and that any given climate is unlikely to be considered satisfactory by all. In fact, it is considered that satisfying $80 \%$ of occupants is good, so a PPD of less that $20 \%$ is good. PMV and PPD provide a measure of the likely response of people. The predicted mean vote is an index from -3 (representing a response of very cold) through 0 (representing a thermally neutral response) to +3 (representing a response of very hot). The predicted percentage dissatisfied is directly related to the predicted mean vote, and so some people suggest that one is redundant. However, from an engineering stance, it is useful to have both 
immediately available. While PPD provides the information as to whether the environment is likely to be acceptable, PMV tells us what the problem is - whether it is too hot or too cold when the number dissatisfied is too large. Human comfort mainly depends on seven factors: activity level, clothing, expectation, air temperature, radiant temperature, humidity and air speed. Fig. 1 and Fig. 2 show thermal comfort zone defined by ASHRAE and ISO 7730 respectively.

Because people typically change their clothing for the seasonal weather Standard 55 specifies summer and winter comfort zones appropriate for clothing insulation levels of 0.5 and 0.9 clo $(0.078$ and $0.14 \mathrm{~m} 2 \cdot \mathrm{K} / \mathrm{W})$, respectively (Figure 4) (ASHRAE 1994). The warmer and cooler temperature borders of the comfort zones are affected by humidity and coincide with lines of constant ET. In the middle region of a zone a typical person wearing the prescribed clothing would have a thermal sensation at or very near neutral.
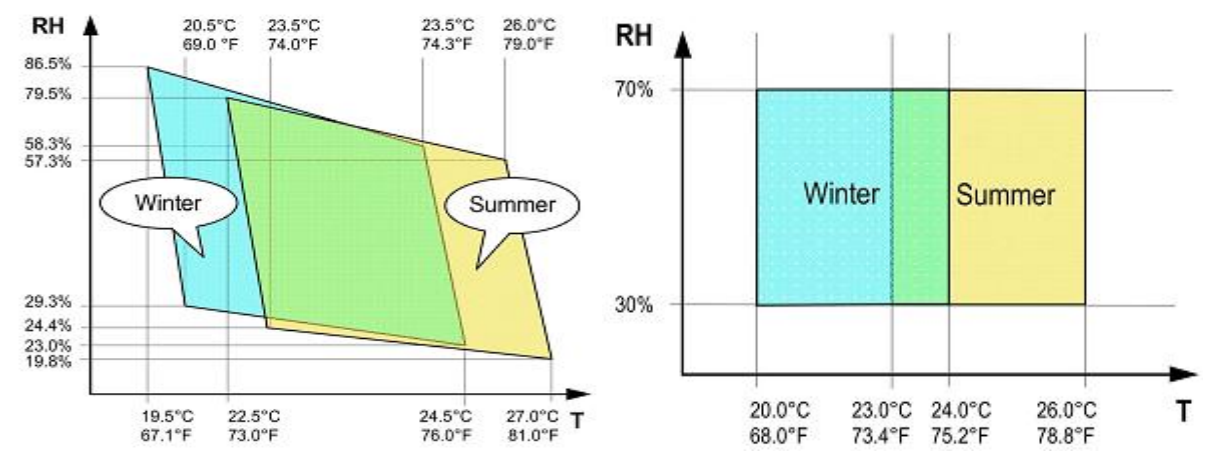

Fig. 1 Comfort zone according to ASHRAE 55-1992 [2]Fig. 2 Comfort zone according to ISO 7730

Following parameters are typically used to determine thermal comfort condition of any space:

\section{A. AQI (Air quality index)}

The AQI is a tool for reporting daily air quality of any city or country. It tells how clean or polluted the air is, and what associated health effects might be a concern for public. The AQI focuses on health effects that one might experience within a few hours or days after breathing polluted air.

TABLE I

APPROVED AIR QUALITY INDEX (AQI) [1]

\begin{tabular}{|c|c|c|}
\hline $\begin{array}{c}\text { Air quality index } \\
\text { (AQI) Range }\end{array}$ & Category & Colour \\
\hline $0-100(1-3)$ & Good & Green \\
\hline $101-200(4-6)$ & Unhealthy & Orange \\
\hline $201-300(7-10)$ & Very Unhealthy & Violet \\
\hline $301-500($ above 10$)$ & Extremely Unhealthy & Red \\
\hline
\end{tabular}

\section{B. PMV (Predicted Mean Vote)}

PMV is an index that predicts the mean value of the votes of a large group of persons on the 7-point thermal sensation scale, based on the heat balance of the human body. Thermal balance is obtained when the internal heat production in the body is equal to the loss of heat to the environment.

\begin{tabular}{|}
\begin{tabular}{|c|c|c|c|c|c|c|}
\hline cold & cool & $\begin{array}{c}\text { Slightly } \\
\text { cool }\end{array}$ & neutral & $\begin{array}{c}\text { Slightly } \\
\text { warm }\end{array}$ & warm & hot \\
\hline-3 & -2 & -1 & 0 & 1 & 2 & 3 \\
\hline
\end{tabular}
\end{tabular}

The PMV index is expressed by P.O. Fanger as

$$
\mathrm{PMV}=\left(0.303 \mathrm{e}^{-0.036 \mathrm{M}}+0.028\right) \mathrm{L}[4]
$$

Where

PMV = Predicted Mean Vote Index

$\mathrm{M}=$ metabolic rate

$\mathrm{L}=$ thermal load - defined as the difference between the internal heat production and the heat loss to the actual environment - for a person at comfort skin temperature and evaporative heat loss by sweating at the actual activity level. 


\section{PPD (Predicted Percent Dissatisfied)}

Predicted Percentage Dissatisfied - PPD - index is a quantitative measure of the thermal comfort of a group of people at a particular thermal environment. This index provides information on thermal discomfort or thermal dissatisfaction by predicting the percentage of people likely to feel too warm or too cool in a given environment.

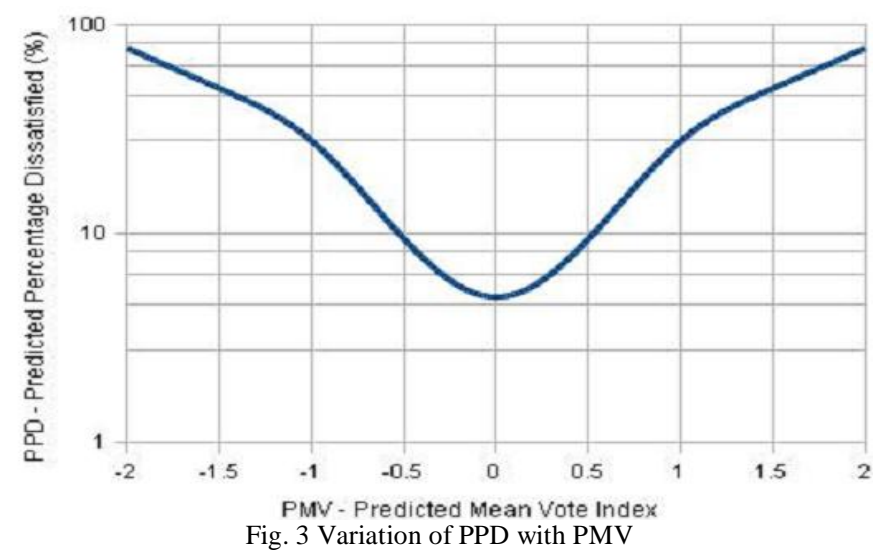

\section{ADPI (Air Diffusion Performance Index)}

A single number rating of the air diffusion performance of a mixing system at specified supply air delivery rate, temperature, moisture content, and space cooling load. ADPI is based on air speed and effective draft temperature. Air Diffusion Performance Index (ADPI) is the percentage of the space in which the air speed is less than $0.35 \mathrm{~m} / \mathrm{s}$ and the Draft Temperature falls between $-1.7^{\circ} \mathrm{C}$ and $1.1^{\circ} \mathrm{C}[2]$.

\section{E. CRE (Contaminant Removal Effectiveness)}

This parameter is an index that provides information on the effectiveness of a ventilation system in removing contaminated air from the whole space. For a perfect mixing system CRE $=1$. Values above 1 are good, values below 1 are poor.

\section{F. LMA (Local Mean Age)}

LMA is the average time for fluid to travel from the selected inlet opening to the point considering both the velocity and diffusion. LMA is defined as follows:

$$
\tau_{\mathrm{p}}=\int_{0}^{\infty} t A p(t) \partial t[5]
$$

where, $A_{p}(t)$ represents the age distribution curve for air arriving at point $p$.

\section{G. LACI (Local Air Change Index)}

LACI (Local Air Change Index) is the ratio of the V/Q value, where V is the computational domain fluid volume and Q is the volume flow rate of the fluid entering this volume, to the average time $\tau$ for the fluid to travel from the selected inlet opening to the point considering both the velocity and diffusion. LACI is defined as follows:

$$
\varepsilon_{\mathrm{p}}=\tau_{\mathrm{n}} / \tau_{\mathrm{p}}[5]
$$

where, $\tau_{\mathrm{n}}$ is nominal time constant of the room (reciprocal of the ventilation air change rate). A value of LACI of unity (1) represents the equivalent of a piston flow with a smaller number representing less effective ventilation. Values greater than unity are possible in the space, for example, in situations where the exhaust is close to the supply, but the mean for the space cannot exceed unity.

\section{Simulation Methodology}

The The first step of flow simulation is to design a computational model. To investigate the indoor air quality and thermal comfort in the buildings, a model hospital room with typical medical appliances and lighting was designed (Fig. 4) in the Solidworks and results were obtained by CFD simulations. 


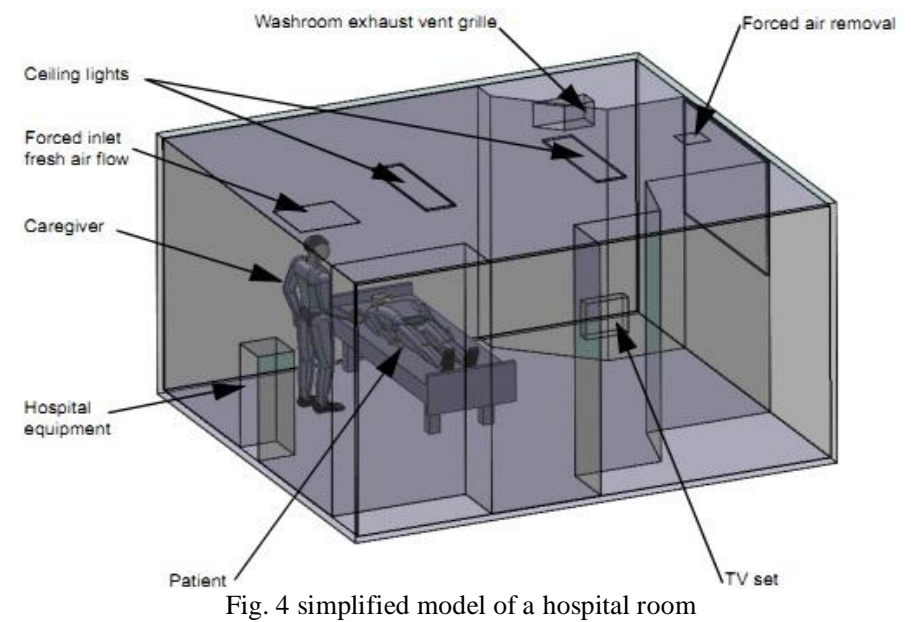

Solidworks flow simulation offers automatic mesh generation for any model. In this problem mesh was generated automatically for the highest result resolution with narrow channel refinement. For better results, mesh optimization option was utilized which applies finer mesh on the critical regions. Moreover minimum wall thickness and gap size were set to $0.012 \mathrm{~m}$, which is equal to the width of the face representing the patient's mouth $(12 \mathrm{~mm})$. To better resolve the complex geometry of the Caregiver and Patient components and more accurately account the heat produced by the heat sources specified at these components, the local initial mesh refinement was employed on caregiver and patient components.

After the meshing and domain definition was complete, the boundary types must be set. Boundary-type specifications define the physical and operational characteristics of the model at those topological entries that represent model boundaries. As, this simulation involves different components with different actions, boundary conditions are defined to model those component zones and their properties. All of the boundaries can be found in Table III.

TABLE III

DEFINED BOUNDARIES

\begin{tabular}{|c|c|c|}
\hline \multicolumn{3}{|c|}{ Boundary Conditions } \\
\hline Faces to apply (Fig. 4) & Type & Rate \\
\hline Forced inlet fresh air flow & Inlet Volume Flow & $4.8 \mathrm{~m}^{3} / \mathrm{min}$ \\
\hline Forced air removal & Outlet Volume Flow & $2.6 \mathrm{~m}^{3} / \mathrm{min}$ \\
\hline Washroom exhaust vent grille & $\begin{array}{l}\text { Outlet environment } \\
\text { pressure }\end{array}$ & $\begin{array}{l}\text { Default values }(101325 \mathrm{~Pa} \\
\left.\text { and } 19.5^{\circ} \mathrm{C}\right)\end{array}$ \\
\hline $\begin{array}{l}\text { A face of the Patient component, } \\
\text { representing the } \\
\text { patient's mouth }\end{array}$ & Inlet Volume Flow & $\begin{array}{l}\text { 12 1/min } \\
\text { Substance Concentrations: } \\
\text { - } \quad \text { Mass fraction of } \\
\text { Air is } 0 \\
\text { - } \\
\text { Expired Air is } 1\end{array}$ \\
\hline Surface of the patient body & Heat source & $81 \mathrm{~W}[2]$ \\
\hline Surface of the caregiver body & Heat source & $144 \mathrm{~W}[2]$ \\
\hline Ceiling Lights & Heat source & Heat Transfer Rate of $120 \mathrm{~W}$ \\
\hline TV set & Heat source & Heat Transfer Rate of $50 \mathrm{~W}$ \\
\hline Hospital equipment & Heat source & Heat Transfer Rate of $50 \mathrm{~W}$ \\
\hline
\end{tabular}

The values of reference parameters were checked: metabolic rate, external work, closing thermal resistance and relative humidity, to calculate comfort parameters such as PMV and PPD. These reference parameters define the approximate heat power produced by a human body depending on the activity and health condition, insulating properties of the closing and humidity of the air. Metabolic rate was set to100 W/ $/ \mathrm{m}^{2}$ [2]. The clothing thermal resistance of $0.11 \mathrm{~K} \cdot \mathrm{m}^{2} / \mathrm{W}$ [2] corresponds to a light working ensemble: light underwear, cotton work shirt with long sleeves, work trousers, woolen socks and shoes. The definition of clothing insulation relates to heat transfer from the whole body and, thus, also includes the uncovered parts of the body, such as head and hands. The relative humidity was set to $55 \%$, which is typical for indoor conditions. 


\section{Results and Discussions}

To The comfort range of thermal comfort in air conditioned spaces in normally considered as

$$
-0.5 \leq \mathrm{PMV} \leq+0.5[3]
$$

corresponding to

$$
\text { PPD }<10 \% \text { [3] }
$$

PPD obtained through simulation was almost 17\% (Table IV). From PPD vs. PMV curve (Fig. 3) for 17\% PPD, PMV should be about \pm 0.70 .

To see how the quality of air with respect to the contained contaminant changes through the room, a cut plot by the LAQI of Expired Air parameter at the distance of $1 \mathrm{~m}$ from the floor - i.e. slightly above the level of the patient's head was created. From the Fig. 5 it is clearly evident that LAQI is almost zero (0-100) (Table I) near the face of the patient i.e. satisfactory for the designed hospital room with provided ventilation system.

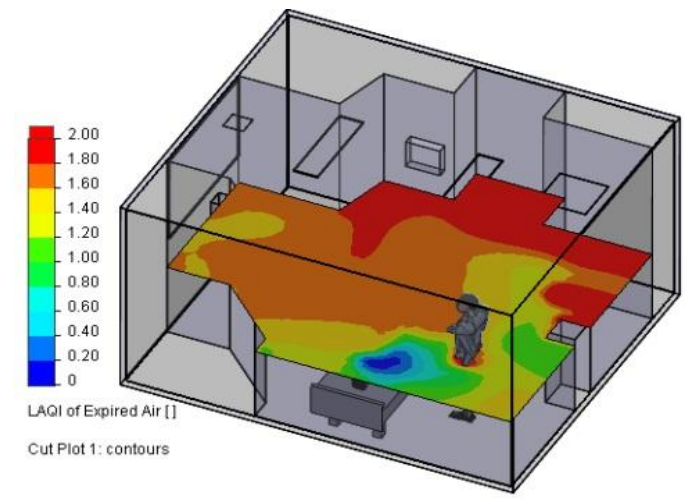

Fig. 5 Cut plot by LAQI of expired air

The isosurfaces of PMV at $0,0.25,0.5,0.75$ and 1 allows estimating the level of thermal comfort through the room - from 0 (normal) to +1 (slightly warm) (Fig. 6). Overall PMV of the room was 0.721211205 (Table IV), which is very close to "Slightly Warm" zone (Table II) and data obtained from PPD vs PMV curve.

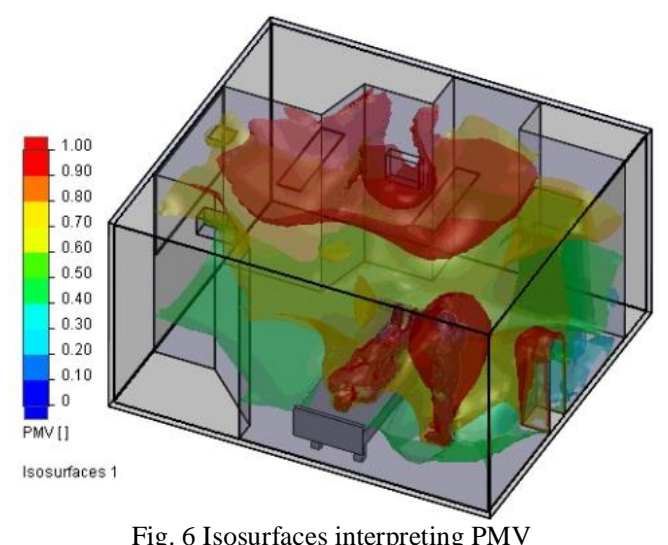

The ADPI is based only on air velocity and effective draft temperature (a combination of local temperature variations from the room average) and is not directly related to the dry-bulb temperature or relative humidity. These and similar effects, such as meanradiant temperature, must be accounted for separately according toASHRAE Standard 55.If several measurements of air velocity and air temperature are made throughout the occupied zone of a room,the ADPI is the percentage of locations where measurements weretaken that meets these specifications for effective draft temperatureand air velocity. If the ADPI is maximum (approaching 100\%), themost desirable conditions are achieved (Miller and Nevins 1969,1970, 1972, 1974; Miller 1971; Miller and Nash 1971; Nevins andWard 1968; Nevins and Miller 1972). Simulated value of ADPI was $63.4301412 \%$.

CRE greater than one is highly required for a perfect ventilation system. The simulation gives CRE of 1.23 for expired air, which means that the ventilation system is reasonably effective in removing the contaminated air.

Numerical results obtained by the simulation are arranged in Table IV. From the overview of the Table IV it is observed that the designed room meets thermal comfort criteria for the provided ventilation system. 
TABLE IV

RESULTS OBTAINED

\begin{tabular}{|l|l|l|}
\hline $\begin{array}{l}\text { Comfort } \\
\text { parameters }\end{array}$ & Units & Value \\
\hline $\begin{array}{l}\text { Mean Radiant } \\
\text { Temperature }\end{array}$ & ${ }^{\circ} \mathrm{C}$ & 23.9847308 \\
\hline $\begin{array}{l}\text { Operative } \\
\text { Temperature }\end{array}$ & ${ }^{\circ} \mathrm{C}$ & 23.4965288 \\
\hline PMV & & 0.721211205 \\
\hline PPD (\%) & & 17.0303015 \\
\hline Draft Temperature & $\mathrm{K}$ & 0.721984015 \\
\hline ADPI $(\%)$ & & 63.4301412 \\
\hline CRE of expired air & & 1.23 \\
\hline
\end{tabular}

\section{Conclusion}

In this study ventilation system performance was investigated with respect to a model hospital room. Comfort and indoor air quality (IAQ) are dependent on many factors, including thermal regulation, control of internal and externalsources of pollutants, supply of acceptable air, removal of unacceptable air, occupants' activities and preferences, and proper operationand maintenance of building systems. Ventilation and infiltrationare only part of the acceptable indoor air quality and thermal comfort problem. Though the result of the study was satisfactory, results obtained through this study are not blindly applicable for hot and humid countries.

The International Standard ASHRAE 55-1992 is used to determine the thermal comfort condition in this study. Unfortunately, current researches have obtained evidences that the standard is irrelevant in predicting the comfort level in the tropical countries especially in the countries with hot and humid climate i.e. Bangladesh (Mallick [6]). One of the reasons, stated by Nicol[7], to the inaccuracy of the standard's prediction is because the small range of the limitation set in the formula. In many case studies conducted in the tropical countries, the measurements recorded, especially in air temperature and velocity are frequently beyond the limitations. The air temperature of $30^{\circ} \mathrm{C}$ is considered normal for this climate and the air movement of more than $1 \mathrm{~m} / \mathrm{s}$ is desirable to relieve the heat.These two figures are set up as the upper limits in the formula.

However, this study was conducted to demonstrate the research methods of investigating thermal comfort criteria in a confined space having predefined ventilation system by HVAC simulation. Same method can be used for hot and humid countries with proper modifications of standard data. For humid and hot countries modification and research methodology of ShafizalMaarof and Phillip Jones [8] can be adapted.

\section{References}

[1] AQI information available at: http:// en.wikipedia.org/wiki/Air quality index

[2] ASHRAE, (1997). ASHRAE Fundamentals Handbook, American Society of Heating, Air-Conditioning and Refrigeration Publishing Service.

[3] Vladimir Zmhral, FrantsekDrkal, "Measurement of thermal comfort parameters in a space with radiant cooled ceiling"

[4] Fanger, P.O. "Thermal comfort-Analysis and application in environmental engineering," Kingsport Press, Inc.,1972

[5] FarhadMemarzadeh, Ph.D., P.E., Andy Manning, Ph.D. "Thermal Comfort, Uniformity, and Ventilation Effectiveness in Patient Rooms: Performance Assessment Using Ventilation Indices," ASHRAE Transactions: Symposia, MN-00-11-3

[6] Mallick, F.H. "Thermal comfort and building design in tropical climate," Energy and Building, 1996, vol 23. pp. 161-167.

[7] Nicol, J.F."Adaptive thermal comfort standards in the hot-humid tropics,"Energy and Buildings, 2004, pp. 628-637.

[8] ShafizalMaarof, Phillip Jones, "Thermal Comfort Factors in Hot and Humid Region: MALAYSIA" 